\title{
Síntese de Copolímeros Metacrílicos Através da Modificação Química do Poli(Metacrilato de Metila) de Massa Molar Controlada
}

\author{
Maria A. F. César-Oliveira, Soraia Zaioncz, Angelo R. S. Oliveira, Maria C. R. Almeida, \\ Sônia F. Zawadzki, Leni Akcelrud, Marcelo Aguiar, David Tabak e Elizabete F. Lucas
}

Resumo: Poli(metacrilato de metila) (PMMA) de massa molar controlada foi sintetizado, em solução de tolueno, utilizando peróxido de benzó́la como iniciador e 1-dodecanotiol (DDM) como agente de transferência de cadeia. O efeito da concentração de DDM sobre a massa molar do PMMA foi investigado. Copolímeros de metacrilato de metila e ácido metacrílico, P(MMA-MAA), foram sintetizados a partir da hidrólise parcial de homopolímeros de metacrilato de metila com variadas massas molares. Utilizando uma técnica inédita na literatura para a síntese de ésteres poliméricos, foi realizada a reação das unidades ácidas do P(MMA-MAA) com álcoois de cadeia longa, na presença de 1,3-diciclocarbodiimida e 4-dimetilamino-piridina, que produziu copolímeros contendo longos segmentos hidrocarbônicos pendentes, tais como o poli(metacrilato de metila-co-metacrilato de hexadecila).

Palavras-chave: Poli(metacrilato de metila), 1-dodecanotiol, poli(metacrilato de metila-co-ácido metacrílico), hidrólise, copolímeros metacrílicos, modificação química.

\section{Introdução}

A síntese de copolímeros metacrílicos é bem conhecida na literatura quando se utiliza a técnica de copolimerização dos comonômeros ${ }^{[1,2]}$. Porém, a modificação química do homopolímero tem sido pouco explorada, apesar destes estudos abrirem a possibilidade de aplicação na reciclagem de artefatos acrílicos.

É de grande interesse comercial o controle da massa molar de um polímero, já que suas propriedades e, conseqüentemente, sua aplicação, dependem dela. Para controlar a massa molar do poli(metacrilato de metila) (PMMA), é comum o uso de agente de transferência de cadeia, na etapa de polimerização, geralmente tióis, devido à sua elevada eficiência frente a monômeros acrílicos. Na polimerização de metacrilato de metila (MMA), 1-dodecanotiol (DDM) encontra-se entre os tióis que apresentam os mais elevados valores de constante de transferência de cadeia ${ }^{[3]}$. Entretanto, o uso de DDM é pouco citado na literatura ${ }^{[3]}$ e sua utilização, em conjunto com peróxido de benzoíla (BPO), ainda não foi reportada.

Visando a obtenção de PMMA de massa molar controlada, o metacrilato de metila (MMA) foi

Maria A. F. César-Oliveira, Soraia Zaioncz, Angelo R. S. Oliveira, Maria C. R. Almeida, Sônia F. Zawadzki, Leni Akcelrud, Marcelo Aguiar, LABPOL, Laboratório de Polímeros Sintéticos, Departamento de Química, UFPR, C.P.: 19082, CEP:81531-970, Curitiba, PR, E-mail:mafco@quimica.ufpr.br; Elizabete F. Lucas, Instituto de Macromoléculas, UFRJ, CEP:21945-970, Rio de Janeiro, RJ; David Tabak, Departamento de Química Orgânica, Instituto de Química, UFRJ, Rio de Janeiro, RJ. 


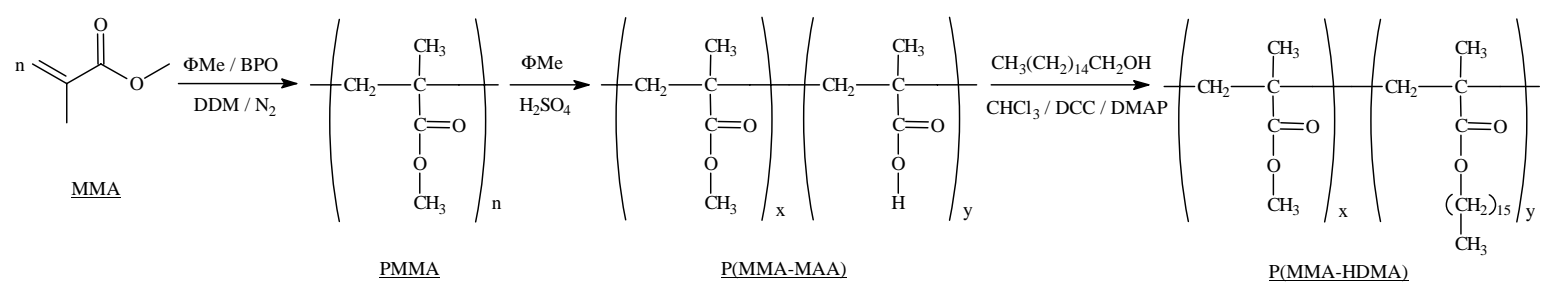

Figura 1. Representação esquemática da síntese de copolímeros metacrílicos a partir do PMMA.

polimerizado em solução utilizando o sistema $\mathrm{BPO} / \mathrm{DDM}$, com variadas proporções de DDM, o que permitiu o estudo do efeito da concentração deste último sobre a massa molar do polímero obtido.

Como parte do estudo da utilização de poli(metacrilato de metila) como precursor de copolímeros metacrílicos, o PMMA obtido foi utilizado na obtenção de copolímeros de metacrilato de metila e ácido metacrílico, P(MMA-MAA), por modificação química da cadeia do PMMA através de reação de hidrólise.

A hidrólise ácida do PMMA de elevada massa molar é encontrada na literatura ${ }^{[4,5]}$. Porém, os procedimentos experimentais descritos não envolvem estudo comparativo da hidrólise parcial de PMMA de massas molares distintas. Para tanto, foi investigada a hidrólise ácida em variadas condições experimentais. Apesar da metodologia mais comum de esterificação de ácidos carboxílicos envolver a reação com um álcool, catalisada por um ácido sulfônico ou pelo ácido sulfúrico, metodologias opcionais são encontradas na literatura. Recentemente, Peracchia e colaboradores ${ }^{[6]}$ descreveram a esterificação de ácido cianoacético com poli(etileno glicol) mono-metoxilado, à temperatura ambiente, na presença de 1,3-diciclohexilcarbodiimida (DCC) e 4-dimetilaminopiridina (DMAP) como catalisador. No presente trabalho, copolímeros de metacrilato de metila e metacrilato de hexadecila, P(MMA-HDMA), foram sintetizados, através da esterificação do P(MMA-MAA), utilizando o método tradicional de catálise ácida e o sistema DCC/DMAP. Este último método é inédito para produtos de partida poliméricos e está representado na Figura 1.

\section{Experimental}

DDM, DCC e DMAP foram usados como recebidos. Todos os demais reagentes e solventes foram previamente purificados e secos.
Síntese de poli(metacrilato de metila) de massa molar controlada

Utilizando aparelhagem própria para refluxo e agitação magnética, o metacrilato de metila foi polimerizado, em atmosfera de nitrogênio seco, em solução de tolueno na concentração de 3 $\mathrm{mol} / \mathrm{L}$ na presença de $25 \mathrm{mmol} / \mathrm{L}$ de BPO $(0,025 \%$ $\mathrm{m} / \mathrm{m}$, em relação ao monômero). Dodecanotiol foi utilizado nas concentrações de zero, 40, 120, 200 e $250 \mathrm{mmol} / \mathrm{L}$. Ao final da reação o solvente foi retirado por destilação azeotrópica em evaporador rotatório, e o resíduo levado até peso constante, para determinação do grau de conversão. O PMMA foi purificado por solubilização em acetona seguida de precipitação em metanol, e seco em estufa a $50^{\circ} \mathrm{C}$.

Síntese de copolímeros de metacrilato de metila e ácido metacrílico

Ácido sulfúrico concentrado, em quantidade suficiente para uma proporção molar PMMA: $\mathrm{H}_{2} \mathrm{SO}_{4}$ de 1:50, foi adicionado a uma solução $5 \mathrm{~mol} / \mathrm{L}$ de PMMA em tolueno, sob agitação magnética. Após a homogeneização do meio reacional, à temperatura ambiente, o mesmo foi aquecido e mantido a $60^{\circ} \mathrm{C}$ por intervalos de tempo variáveis. Ao final da reação, a mistura reacional foi imersa em banho de gelo e vertida cuidadosamente em água gelada, sob agitação. O produto foi precipitado por adição de isopropanol e, em seguida, filtrado sob pressão reduzida e lavado com água até $\mathrm{pH}$ 5. O produto foi seco em estufa a $50^{\circ} \mathrm{C}$ por 24 horas, seguido de secagem a $50^{\circ} \mathrm{C}$, em pistola Abderhalden contendo pentóxido de fósforo, à pressão reduzida.

Síntese de copolímeros de metacrilato de metila e metacrilato de hexadecila

Método A. O P(MMA-MAA) sintetizado foi filtrado à pressão reduzida. Ao produto úmido contendo ácido sulfúrico foram adicionados ex- 
cesso de álcool cetílico e tolueno. O meio reacional foi aquecido em banho de óleo a $90-100^{\circ} \mathrm{C}$, sob agitação magnética, por 12 horas, e os azeótropos tolueno/água e tolueno/metanol foram destilados à medida que foram produzidos. O solvente da reação foi removido em evaporador rotatório.

Método B. A uma solução de P(MMA-MAA) em diclorometano foram adicionados o álcool cetílico seco (em excesso de $10 \mathrm{~mol} \%$ ), DCC (em excesso de $10 \mathrm{~mol} \%$, em relação ao teor de $\mathrm{COOH}$ ) e quantidade catalítica de DMAP. A reação foi realizada em atmosfera de $\mathrm{N}_{2}$, durante 12 horas, sob agitação magnética, à temperatura ambiente. Ao final da reação, o produto foi precipitado em metanol. A solução sobrenadante foi retirada e o precipitado lavado com metanol até total remoção do álcool cetílico não reagido. Nos dois métodos o produto foi purificado por solubilização em acetona e precipitação em metanol, e seco a $50^{\circ} \mathrm{C}$ até peso constante.

\section{Análise dos produtos de reação}

Todos os produtos obtidos foram analisados por FTIR em espectrômetro BOMEM, modelo MB100. Os melhores espectros foram obtidos quando uma solução de PMMA em clorofórmio foi evaporada sobre célula de brometo de potássio, em estufa. $\mathrm{O}$ espectro do filme sólido entre células de $\mathrm{KBr}$ foi realizado com 20 scans e resolução de $4 \mathrm{~cm}^{-1}$. Nos casos em que o teor de MAA no P(MMA-MAA) foi mais elevado, as amostras foram preparadas por evaporação do produto dissolvido em metanol, sobre célula de seleneto de zinco.

A determinação do índice de acidez do produto obtido foi feita através de adaptações de técnicas descritas na literatura ${ }^{[4,5,7]}$. Foi utilizada titulação direta com solução metanólica $0,01 \mathrm{~mol} / \mathrm{L}$ de $\mathrm{KOH}$, previamente padronizada, tendo como indicador solução alcoólica de fenolftaleína. O teor de unidades de ácido metacrílico presentes no copolímero também foi determinado por retro-titulação através da reação de alíquotas do produto seco com solução padronizada de hidróxido de potássio em metanol, por 12 horas, seguida de titulação da base residual com solução padronizada de ácido sulfúrico. O ponto final da reação foi visualizado utilizando-se solução do indicador azul de bromo timol. Os resultados dos dois métodos foram comparados.
Tabela 1. Resultados experimentais da polimerização de MMA, com variadas concentrações de DDM.

\begin{tabular}{ccccccc}
\hline \multirow{2}{*}{$\begin{array}{c}\text { [DDM] } \\
(\mathbf{m m o l} / \mathbf{L})\end{array}$} & $\begin{array}{c}\text { Conv. } \\
(\boldsymbol{\%})\end{array}$ & $\langle\mathbf{M n}\rangle$ & $\langle\mathbf{M w}\rangle$ & \multicolumn{2}{c}{ Redução $(\%)$} \\
\cline { 5 - 6 } & & & & $\langle\mathbf{M n}\rangle$ & $\langle\mathbf{M w}\rangle$ \\
\hline Zero & 56 & 40255 & 130196 & - & - \\
40,0 & 90 & 13329 & 31478 & 67 & 76 \\
120,0 & 70 & 7348 & 15449 & 82 & 88 \\
200,0 & 73 & 3691 & 6684 & 91 & 95 \\
250,0 & 67 & 2532 & 4720 & 94 & 96 \\
\hline
\end{tabular}

As análises por GPC foram realizadas utilizando-se tetra-hidrofurano como solvente, em equipamento Waters, modelo 600-E, dotado de detetor de índice de refração e conjunto de colunas Ultrastyragel $\left(10^{3}\right.$ a $\left.10^{6} \AA\right)$.

Os espectros de NMR foram obtidos em espectrômetros BRUKER de 80 e $200 \mathrm{MHz}$. As análises dos produtos de reação, por NMR, foram realizadas a $28^{\circ} \mathrm{C}$, em soluções a $4 \%(\mathrm{~m} / \mathrm{V})$ em $\mathrm{CDCl}_{3}$. As análises do P(MMA-MAA) contendo elevados teores de MAA foram feitas em DMSO- $\mathrm{d}_{6}$.

\section{Resultados e Discussão}

\section{Síntese de poli(metacrilato de metila) de massa} molar controlada

A polimerização do MMA foi conduzida em várias condições de temperatura e tempo de reação. Os maiores valores de conversão foram obtidos a $90^{\circ} \mathrm{C}$ e 17 horas de reação e os melhores rendimentos foram alcançados por solubilização do produto bruto em acetona e precipitação em metanol, na pro-



Figura 2. Efeito da concentração de DDM na massa molar média do PMMA. 


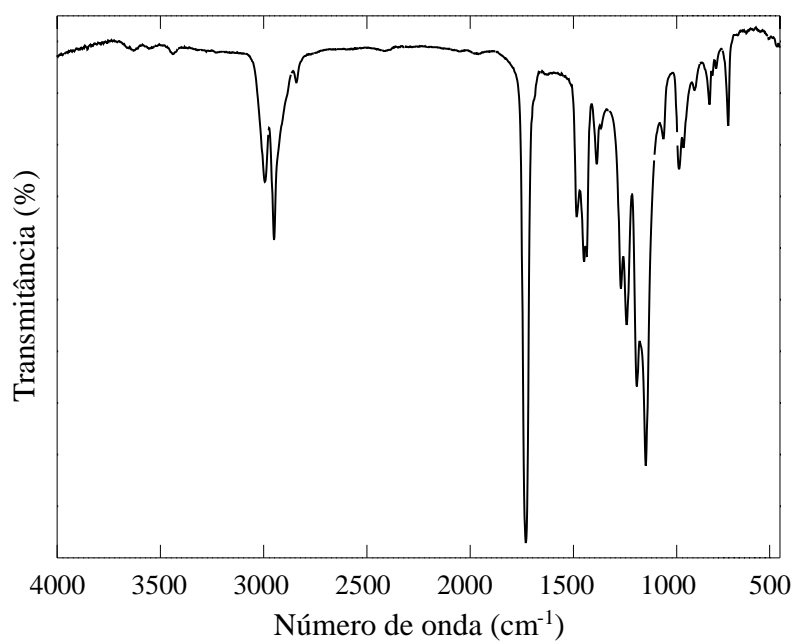

Figura 3. Espectros de FTIR e ${ }^{1} \mathrm{H}-\mathrm{NMR}$ do PMMA.

porção 1:6 (V/V). Estas condições foram utilizadas para a realização das reações com variadas concentrações de DDM. Para cada concentração de DDM foram realizadas reações em triplicata e os produtos foram analisados por GPC. Deste modo, foi possível avaliar a influência da concentração de DDM sobre a massa molar dos polímeros sintetizados.

O valor médio dos resultados experimentais estão mostrados na Tabela 1. Foi possível observar que a utilização de $40 \mathrm{mmol} / \mathrm{L}$ de $\operatorname{DDM}(1,33$ mol\%, em relação ao monômero) promove uma queda acentuada da massa molar do PMMA (67\%) chegando a uma redução de $90 \%$ com a adição de $200 \mathrm{mmol} / \mathrm{L}$ de $\mathrm{DDM}(6,67 \mathrm{~mol} \%$, em relação ao monômero). Na Figura 2 a redução da massa molar fica melhor evidenciada.

A análise por FTIR e ${ }^{1} \mathrm{H}-\mathrm{NMR}$ confirmou a identidade e a pureza dos reagentes e dos produtos de reação. A interpretação dos espectros de FTIR e ${ }^{1} \mathrm{H}$ NMR, mostrados na Figura 3, foi feita com base na literatura $^{[1]}$. Os picos na região de $\delta=0,8-1,0 \mathrm{ppm}$ podem ser atribuídos aos hidrogênios do grupo metila, cujo deslocamento químico é influenciado pela taticidade do polímero. O mesmo efeito ocorre nos sinais correspondentes aos hidrogênios do grupo metileno ( $\delta=1,6-1,9 \mathrm{ppm})$. Os hidrogênios correspondentes ao grupo $\mathrm{O}-\mathrm{CH}_{3}$ podem ser observados como um singlete em $\delta=3,6 \mathrm{ppm}$.

\section{Síntese de copolímeros de metacrilato de metila e ácido metacrílico}

Inicialmente foi realizada a hidrólise do PMMA $(<\mathrm{Mn}>=3000)$ em ácido sulfúrico concentrado, à

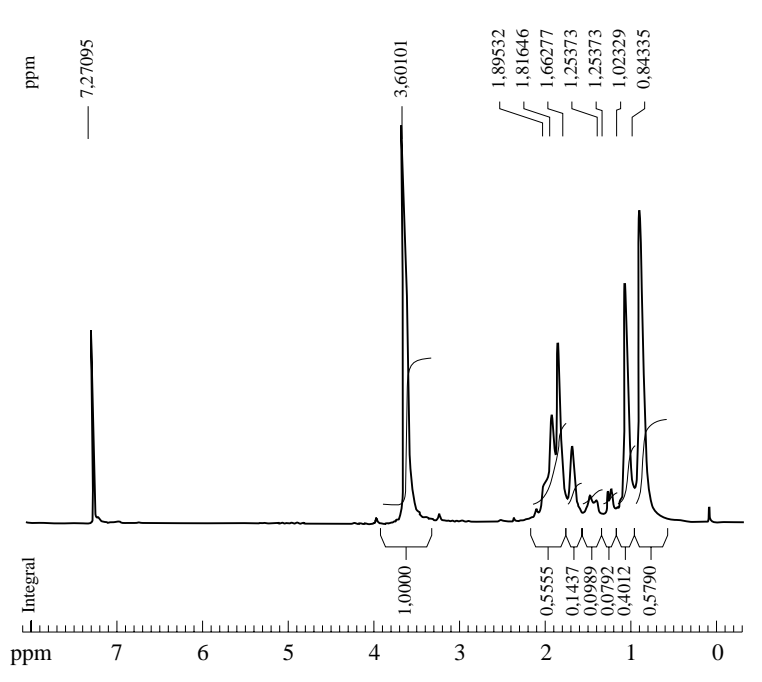

temperatura ambiente, em meio heterogêneo seguindo o experimental descrito por Smith ${ }^{[5]}$ para PMMA de $<\mathrm{Mn}>=600000$. O aparecimento de bandas pouco intensas de O-H de ácido carboxílico nas regiões de 3200 e $2600 \mathrm{~cm}^{-1}$, inexistentes no espectro do $\mathrm{PMMA}^{[5]}$, revelou o baixo grau de hidrólise do produto.

Foram realizadas diversas reações de hidrólise, na tentativa de aumentar o índice de acidez do copolímero, tendo como variáveis o tempo de reação e a massa molar do PMMA. O baixo grau de hidrólise do produto de reação $(2,42 \mathrm{~mol} \%)$ foi comprovado pelo aparecimento de uma banda de $\mathrm{O}-\mathrm{H}$ de ácido carboxílico $\left(3280 \mathrm{~cm}^{-1}\right)$ pouco intensa no espectro de FTIR. Na tentativa de separação de uma fração de maior grau de hidrólise, após lavagem do produto de reação até $\mathrm{pH} 5$, o mesmo foi tratado com metanol. Amostras secas das duas frações do produto de reação (fração insolúvel e fração solúvel em metanol) foram tituladas. A fração solúvel em metanol apresentou um grau de hidrólise de $3,09 \mathrm{~mol} \%$ e a fração insolúvel, $0,91 \mathrm{~mol} \%$.

Um novo procedimento experimental de hidrólise ácida foi investigado, baseado na metodologia descrita por Leyte e colaboradores ${ }^{[4]}$ para hidrólise total de PMMA de elevada massa molar através da solubilização do PMMA em ácido sulfúrico concentrado, na proporção molar de $1: 100$, à temperatura ambiente, seguida da reação a $60^{\circ} \mathrm{C}$, por duas horas. Como é de nosso interesse a hidrólise parcial do PMMA, o tempo de reação, a $60^{\circ} \mathrm{C}$, foi inicialmente reduzido à metade. Por comparação com a intensidade da banda de carbonila, a intensa banda de O-H de ácido carboxílico obser- 
Tabela 2. Composição do P(MMA-MAA) obtido por hidrólise em $\mathrm{H}_{2} \mathrm{SO}_{4}(1: 100)$ a $60^{\circ} \mathrm{C}$.

\begin{tabular}{|c|c|c|}
\hline \multirow{2}{*}{$\begin{array}{c}\Delta \mathbf{t} \\
(\mathbf{m i n})\end{array}$} & \multicolumn{2}{|c|}{ Composição (mol \%) } \\
\hline & СOOH & COOMe \\
\hline 0 & 0 & 100 \\
\hline 15 & 43 & 57 \\
\hline 30 & 51 & 49 \\
\hline 60 & 53 & 47 \\
\hline 75 & 53 & 47 \\
\hline 120 & 61 & 39 \\
\hline
\end{tabular}

vada a $3160 \mathrm{~cm}^{-1}$, acompanhada da banda também característica de ácido carboxílico a $2613 \mathrm{~cm}^{-1}$, ambas citadas na literatura ${ }^{[5]}$, comprovaram que a hidrólise ocorreu em extensão bem superior à dos experimentos já realizados.

O mesmo procedimento experimental foi utilizado para hidrólise de amostras de PMMA de diferentes massas molares, permitindo constatar que a massa molar e a granulometria do PMMA afetam o tempo de solubilização do polímero no ácido reagente, provocando a variação do tempo total de reação.

Para possibilitar o estudo da influência do tempo de reação e da massa molar do PMMA sobre o grau de hidrólise, optou-se pela introdução de um solvente inerte (tolueno) visando minimizar o tempo de homogeneização do meio reacional antes do início do aquecimento.

$\mathrm{Na}$ etapa de isolamento do produto de reação, uma fração do produto permaneceu emulsionada

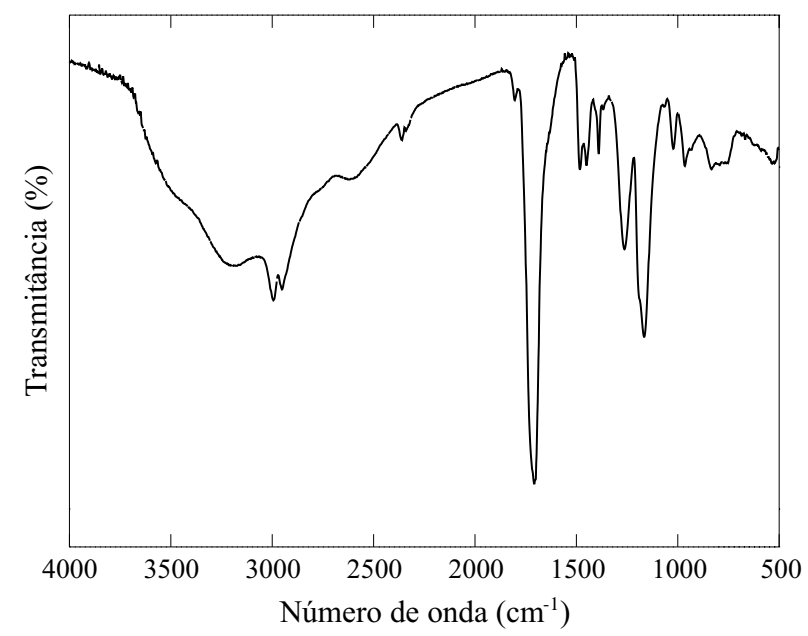

Figura 5. Espectros de FTIR e ${ }^{1} \mathrm{H}-\mathrm{NMR}$ do P(MMA-MAA) (47:53).

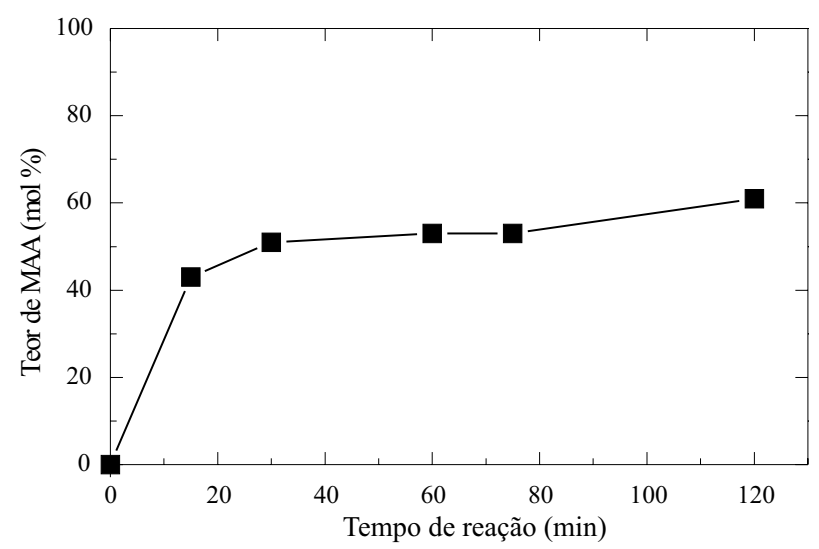

Figura 4. Curva do teor de MAA "versus" tempo de reação do $\mathrm{P}$ (MMA-MAA) obtido por hidrólise em $\mathrm{H}_{2} \mathrm{SO}_{4}(1: 100)$ a $60^{\circ} \mathrm{C}$.

no filtrado. A adição subseqüente de isopropanol foi uma modificação importante que promoveu a precipitação do copolímero, inicialmente em suspensão, tornando a filtração fácil e rápida e a lavagem do produto, para retirada do ácido residual, muito mais eficiente. $\mathrm{O}$ resultado da titulação do produto de reação purificado através da solubilização em N,N-dimetilformamida e precipitação em água ${ }^{[5]}$ foi idêntico ao da fração do produto não submetido à purificação, mostrando que a etapa de purificação era desnecessária.

As modificações introduzidas produziram um único produto sólido cujo grau de hidrólise foi diretamente proporcional ao tempo de reação. A composição dos copolímeros obtidos por hidrólise do PMMA $(<\mathrm{Mn}>=3078 ;<\mathrm{Mw}>=7921)$ em ácido sulfúrico (1:100) foi determinada por titulação direta, na presença de fenolftaleína. Os valores estão mostrados na Tabela 2 e plotados em gráfico na Figura 4.

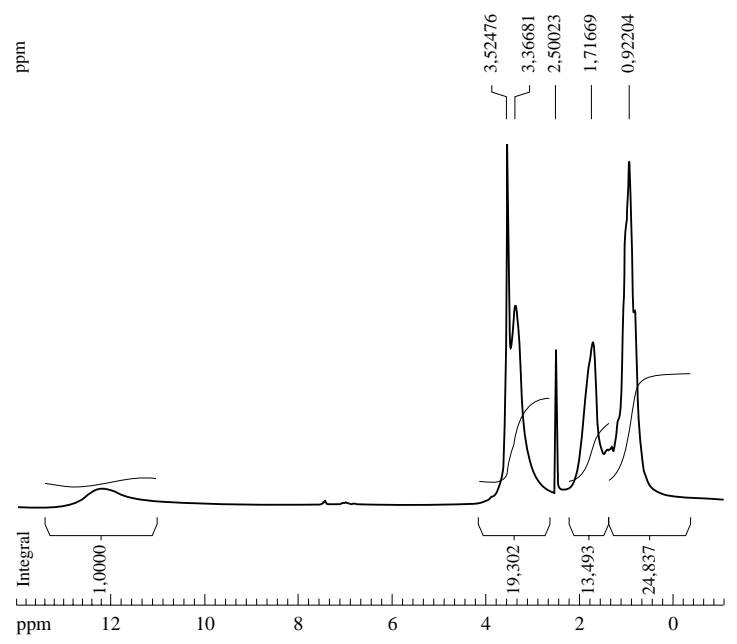


Na Figura 5 é possível observar principalmente a presença de bandas largas em 3180 e $2620 \mathrm{~cm}^{-1}$, inexistentes no espectro de FTIR do PMMA (Figura 3) atribuídas à $\mathrm{O}-\mathrm{H}$ de ácido carboxílico ${ }^{[5]}$. No espectro de ${ }^{1} \mathrm{H}-\mathrm{NMR}$, a presença de um singlete largo em 12,2 ppm, atribuído ao hidrogênio ácido das unidades de MAA, e do singlete em $\delta=3,5 \mathrm{ppm}$, atribuído ao $\mathrm{O}-\mathrm{CH}_{3}$ das unidades de MMA comprovam a formação do copolímero P(MMA-MAA).

Uma vez que no procedimento experimental desenvolvido, o ácido sulfúrico não mais exerce papel de solvente, foi introduzida uma nova modificação reduzindo a proporção PMMA: $\mathrm{H}_{2} \mathrm{SO}_{4}$ de 1:100, indicada por Leyte ${ }^{[4]}$, para 1:50, acelerando a etapa de lavagem do produto e evitando a queda do rendimento da reação. Os resultados experimentais da hidrólise ácida do PMMA $(<\mathrm{Mn}>=3596 ;<\mathrm{Mw}>=$ $6553)$, expressos na Tabela 3 e no gráfico da Figura 6 , mostram que o grau de hidrólise é proporcional ao tempo de reação e que, apesar dos valores obtidos não serem exatamente os mesmos dos experimentos anteriores correspondentes, são comparavelmente elevados. Esta metodologia foi usada no estudo da influência da massa molar do PMMA sobre a composição dos copolímeros.

Inicialmente optou-se pela determinação do teor de unidades de ácido metacrílico através da titulação potenciométrica de soluções do copolímero utilizando eletrodo de vidro combinado ${ }^{[4,5]}$. Porém, uma vez que o copolímero não é solúvel em água, a necessidade de adição de variadas proporções de um solvente orgânico (como metanol, DMF ou acetona) dificulta a estabilização do potenciômetro, inviabilizando a leitura dos valores de $\mathrm{pH}$. Partiuse, então, para a titulação direta (ácido fraco-base forte) com a utilização de indicadores de cor citados na literatura, como a fenolftaleína ${ }^{[5,8]}$. Como a coloração da fenolftaleína em meio alcalino tam-

Tabela 3. Teor de MAA no P(MMA-MAA) obtido por hidrólise em $\mathrm{H}_{2} \mathrm{SO}_{4}(1: 50)$ a $60^{\circ} \mathrm{C}$.

\begin{tabular}{ccc}
\hline $\begin{array}{c}\text { Tempo de reação } \\
(\mathbf{m i n})\end{array}$ & $\begin{array}{c}\text { Titulação direta } \\
\text { MAA } \\
(\mathbf{m o l} \%)\end{array}$ & $\begin{array}{c}\text { Titulação inversa } \\
\text { MAA } \\
(\mathbf{m o l} \%)\end{array}$ \\
\hline 0 & 0 & 0 \\
30 & 57 & 39 \\
60 & 58 & 46 \\
120 & 61 & 51 \\
180 & 61 & 55 \\
\hline
\end{tabular}

bém não é estável, em alguns casos um grande número de análises teve que ser realizado para a obtenção de um resultado confiável. Optou-se, então, pela retro-titulação dos copolímeros visando uma reação mais eficiente com os grupamentos ácidos presentes no produto e a posterior titulação (ácido forte-base forte), utilizando um indicador estável, azul de bromo timol. Os resultados obtidos na titulação direta e na retro-titulação podem ser comparados através dos dados da Tabela 3 , representados no gráfico da Figura 6.

Com base nos resultados obtidos, foi possível avaliar a influência da massa molar sobre o teor de unidades de ácido metacrílico dos copolímeros produzidos por hidrólise do PMMA em ácido sulfúrico (1:50). A composição dos copolímeros obtidos a partir do PMMA de massa molar variada, em 1 hora de reação, a $60^{\circ} \mathrm{C}$, foram determinados por retro-titulação usando azul de bromo timol e estão dispostos na Tabela 4.

Síntese de copolímeros de metacrilato de metila e metacrilato de hexadecila

Uma vez que antes da lavagem do produto de hidrólise, o $\mathrm{pH}$ da mistura é extremamente ácido

Tabela 4. Composição do P(MMA-MAA) obtido por hidrólise do PMMA de massa molar variada.

\begin{tabular}{ccc}
\hline \multirow{2}{*}{ PMMA<Mn> } & \multicolumn{2}{c}{ Titulação inversa } \\
\cline { 2 - 3 } & MAA (mol\%) & MMA (mol\%) \\
\hline 3600 & 46 & 54 \\
40000 & 37 & 63 \\
260000 & 36 & 64 \\
\hline
\end{tabular}

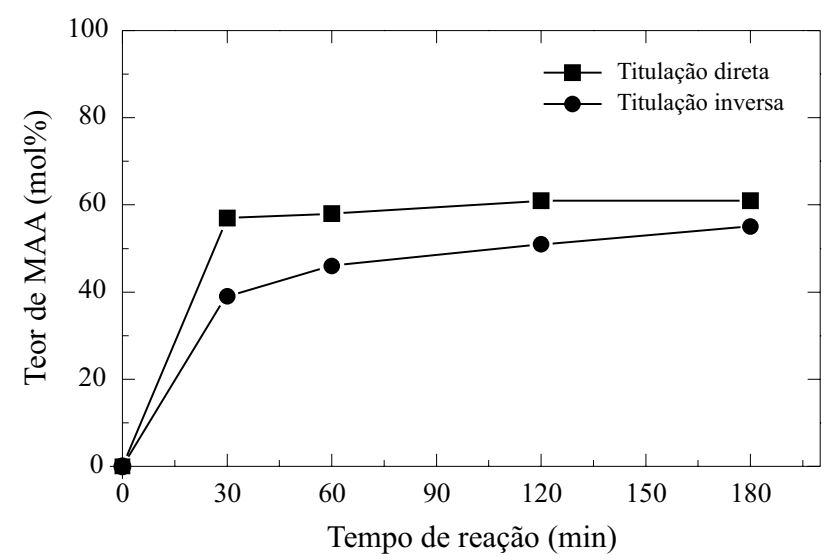

Figura 6. Curva do teor de MAA versus tempo de reação do P(MMAMAA) obtido por hidrólise em $\mathrm{H}_{2} \mathrm{SO}_{4}(1: 50)$ a $60^{\circ} \mathrm{C}$. 
Tabela 5. Resultados experimentais da esterificação do P(MMA-MAA) com álcool cetílico.

\begin{tabular}{cccc}
\hline Sistema & $\begin{array}{c}\text { Teor de MAA (mol\%) } \\
\text { (produto hidrolisado) }\end{array}$ & $\begin{array}{c}\text { Teor de MAA (mol\%) } \\
\text { (produto esterificado) }\end{array}$ & Grau de esterificação (\%) \\
\hline DCC / DMAP & 2,41 & 0,20 & 92 \\
$\mathrm{H}_{2} \mathrm{SO}_{4}$ & 2,37 & 0,66 & 72 \\
\hline
\end{tabular}

( $\mathrm{pH}=1)$, o número de etapas sintéticas foi reduzido, utilizando o resíduo de ácido sulfúrico presente no produto hidrolisado, como catalisador, e procedendo a secagem dos produtos de partida, "in situ", por destilação azeotrópica com tolueno. A análise por FTIR foi uma técnica bastante útil no acompanhamento da etapa de purificação, através do monitoramento da banda de O-H do álcool (3400 $\left.\mathrm{cm}^{-1}\right)$. Os resultados da análise volumétrica do produto de reação, comparados aos resultados encontrados para o produto de partida, demonstraram um elevado grau de esterificação. O índice de acidez residual do produto foi determinado por titulação ácido-base, seguindo o mesmo procedimento experimental descrito anteriormente. Os resultados obtidos pelos dois métodos de esterificação estão dispostos na Tabela 5. As análises por FTIR e ${ }^{1} \mathrm{H}-$ NMR do produto esterificado não foram conclusivas pois, devido ao baixo teor de unidades HDMA, os espectros são muito semelhantes aos do PMMA.

Apesar da esterificação catalisada por ácido sulfúrico ter se mostrado eficiente, com a vantagem adicional de dispensar as etapas de secagem de produto de partida e reagentes, a comparação com os resultados da esterificação do produto seco apontam ser esta última bem mais eficiente, apresentando esterificação quase completa dos grupamentos ácidos, que podem ser atribuídos, principalmente, à ativação da carbonila pelo uso do DCC.

\section{Conclusão}

Elevadas conversões de metacrilato de metila foram obtidas nas polimerizações em tolueno com variadas concentrações de DDM. As reações de polimerização apresentaram boa reprodutibilidade de resultados e redução de até $90 \%$ na massa molar com o uso de pequenas proporções do agente de transferência de cadeia. $\mathrm{Na}$ obtenção do poli(metacrilato de metila-co- ácido metacrílico), os melhores resultados foram obtidos por hidrólise em ácido sulfúrico concentrado, a $60^{\circ} \mathrm{C}$, de uma solução de PMMA) em tolueno. A nova metodologia de hidrólise ácida desenvolvida possibilitou a realização da reação em meio homogêneo, independente da massa molar do PMMA, para a obtenção dos copolímeros P(MMA-MAA) contendo elevados e variados teores de ácido metacrílico. $\mathrm{Na}$ obtenção do poli(metacrilato de metila-cometacrilato de hexadecila), a metodologia envolvendo o sistema DCC/DMAP, inédito na literatura para polímeros, mostrou-se bem mais eficiente, levando a um grau de esterificação de $92 \%$ em relação a $72 \%$ do sistema catalisado por ácido sulfúrico.

\section{Agradecimento}

CNPq; CNPq-PIBIC/UFPR; LABES/DQ/ UFPR; FUNPAR/UFPR; DQ/UFPR; IQ/UFRJ (LAPOCAT e Laboratório de RMN)

\section{Referências Bibliográficas}

1. Vangani, V.; Rakshit, A. K. - J. Appl. Polym. Sci. 60, 1005 (1996).

2. Agarwal, S. et al. - Def. Sci. J. 47, 401 (1997).

3. Jahanzad, F., et al. - Polymer 34, 3542 (1993).

4. Leyte, J. C. - J. Phys. Chem. 76, 2559 (1972).

5. Smith, P.; Goulet, L. - J. Polym. Sci.: Part B: Polym. Phys. 31, 327 (1993).

6. Peracchia, M.T. et al. - Macromolecules 30, 846 (1997).

7. Zawadzki, S.F. - Tese de Mestrado. Instituto de Química-UFRJ. Rio de Janeiro (1989). 